\title{
Study on Antenna Mutual Coupling Suppression Using Integrated Metasurface Isolator for SAR and MIMO Applications
}

\author{
Mohammad Alibakhshikenari ${ }^{1}$, Bal Singh Virdee ${ }^{2}$, Chan H. See ${ }^{3}$, Raed Abd-Alhameed ${ }^{4}$, Francisco Falcone ${ }^{5}$, \\ Aurora Andújar ${ }^{6}$, Jaume Anguera ${ }^{6,7}$, and Ernesto Limiti ${ }^{1}$ \\ ${ }^{1}$ Electronics Engineering Department, University of Rome "Tor Vergata", Italy \\ ${ }^{2}$ London Metropolitan University, Center for Communications Technology \& Mathematics, UK \\ ${ }^{3}$ School of Engineering Department, University of Bolton, UK \\ ${ }^{4}$ School of Electrical Engineering \& Computer Science, University of Bradford, UK \\ ${ }^{5}$ Electric and Electronic Engineering Department, Universidad Pública de Navarra, Spain \\ ${ }^{6}$ Fractus Antennas, Spain \\ ${ }^{7}$ Department of Electronics and Telecommunication, Universitat Ramon Llull, Spain \\ \{alibakhshikenari, limiti\}@ing.uniroma2.it, b.virdee@londonmet.ac.uk, c.see@bolton.ac.uk,r.a.a.abd@bradford.ac.uk, \\ francisco.falcone@unavarra.es, aurora.andujar@fractus.com, jaumean@salleurl.edu
}

\begin{abstract}
A metasurface based decoupling structure that is composed of a square-wave slot pattern with exaggerated corners that is implemented on a rectangular microstrip provides highisolation between adjacent patch antennas for Synthetic Aperture Radar (SAR) and Multi-Input-Multi-Output (MIMO) systems. The proposed $1 \times 2$ symmetric array antenna integrated with the proposed decoupling isolation structure is designed to operate at ISM bands of $\mathrm{X}, \mathrm{Ku}, \mathrm{K}$, and $\mathrm{Ka}$. With the proposed mutual coupling suppression technique (i) the average isolation in the respective ISM bands listed above is $7 \mathrm{~dB}, 10 \mathrm{~dB}, 5 \mathrm{~dB}$, and 10 $\mathrm{dB}$; and (ii) edge-to-edge gap between adjacent radiation elements is reduced to $10 \mathrm{~mm}(0.28 \lambda)$. The average antenna gain improvement with the metasurface isolator is $2 \mathrm{dBi}$.
\end{abstract}

Keywords - Mutual coupling suppression, decoupling, metasurface, synthetic aperture radar (SAR), MIMO.

\section{INTRODUCTION}

Wireless communications systems using single channel full-duplex (SCFD) simultaneously transmit and receive radiosignals on the same frequency channel. Although SCFD is more efficient than time-division and frequency-division duplexing systems it's not popular because of self-interference resulting from leaked signals at the receiver from its own transmitter. This can be seriously debilitating especially in low-power systems with sensitive receivers [1]. To enable the widespread use of SCFD it is therefore important to reduce or mitigate the effects of self-interference.

Techniques to suppress self-interference include antenna cancellation, radio-frequency/analogue cancellation, and digital base-band cancellation. Antenna cancellation is considered essential as analogue cancellation is not effective by itself to prevent saturation low-noise amplifier and analogto-digital converter prior to a digital base-band cancellation. Antenna spacing is one means of minimising the effects of self-interference, however it requires multiple antennas and greater space [1-2]. Other cancellation techniques investigated to date include (i) orthogonal polarized antennas [3, 4]; (ii) colocated antennas with a beamforming feed network $[5,6]$; orthogonal polarized planar array antennas [7-9]; and selfinduced destructive interference [1-9]. Array and co-located antennas in [5-9] perform self-cancellation recursively as array size gets bigger.

In this paper, a unique decoupling structure is shown to provide high-isolation between nearby patch antennas. The decoupling structure is located between the two antennas to cancel self-interference. It is essentially a metasurface that consists of a square-wave slot pattern with exaggerated corners etched on a rectangular microstrip. This technique is shown to offer an average of $10 \mathrm{~dB}$ of mutual coupling suppression.

\section{Proposed $1 \times 2$ SYMmetric ARRAY ANTENNA WITH THE PROPOSED DECOUPLING ISOLATOR}

Self-interference between the transmit and receive (TRx) array antenna results from insufficient $\mathrm{TRx}$ isolation characteristic of an array element and the mutual couplings between the array elements. Strength of spatial couplings in the array antenna is determined by the spacing between the array elements and geometry of the antenna, whereas the TRx isolation of the array element determines the direct coupling.

It is necessary to effectively suppress self-interference at each Rx-port of the array elements to realize acceptableisolation. A symmetric array is preferred because each coupled signal has its counterpart (a signal with same power and/or same phase) at other ports, and simply adding them destructively in an Rx using the decoupling structure would result in higher isolation. Fig. 1(a) depicts a symmetric layout for a $1 \times 2$ array, where each radiation element is excited separately. Fig. 1(b) shows the proposed decoupling structure 
or metasurface that is composed of a square-wave slot pattern with exaggerated corners that is implemented on a rectangular microstrip. The corners were exaggerated to enhance the isolation. This decoupling structure is integrated between the antennas in the array as shown in Fig. 1(c) to reduce selfinterference. The array was designed to operate at ISM bands of $\mathrm{X}, \mathrm{Ku}, \mathrm{K}$, and $\mathrm{Ka}$, and constructed on FR-4 lossy substrate with dielectric constant of $\varepsilon_{r}=4.3, \tan \delta=0.025$, and thickness of $1.6 \mathrm{~mm}$. Each element in the array was directly fed with a required current (amplitude and phase) to achieve a high-gain directional beam at the boresight.

S-parameters including reflection coefficient $\left(\left|S_{11}\right| \leq\right.$ $-10 \mathrm{~dB})$ and mutual coupling $\left(S_{12}\right)$ were obtained using 3D full-wave simulators (CST Microwave Studio ${ }^{\text {TM }}$ and HFSS). The results of the simulation in Fig. 2 show the reference array with no decoupling structure in the four frequency bands (X, $\mathrm{Ku}, \mathrm{K}$, and $\mathrm{Ka}$ ) has maximum and average isolation values of $-26 \mathrm{~dB} \&-25.5 \mathrm{~dB},-27.13 \mathrm{~dB} \&-23.5 \mathrm{~dB},-25 \mathrm{~dB} \&-23 \mathrm{~dB}$, and $-46.5 \mathrm{~dB} \&-35 \mathrm{~dB}$, respectively. The S-parameters are listed in Table 1.

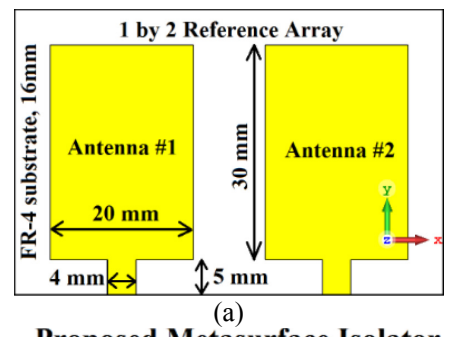

Proposed Metasurface Isolator

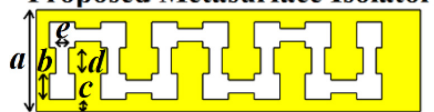

$a, b, c, d$, and $e$ are $8,2,1,2$, and $1 \mathrm{~mm}$, respectively

(b)

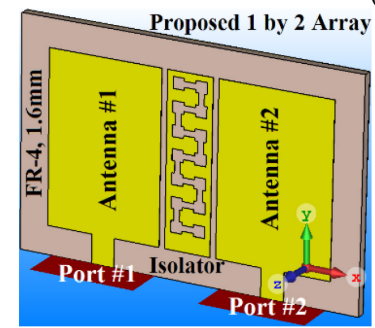

(c)

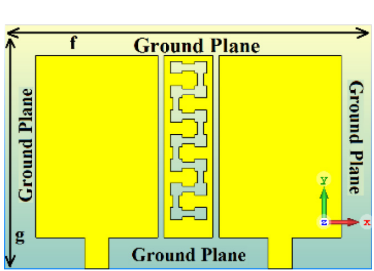

(d)
Fig. 1. Configuration of (a) reference array antennas, (b) proposed integrated closed isolator based on metasurface, (c) proposed array antennas applying the proposed decoupling slab, and (d) ground-plane of both structures, $f$ and $g$ are $60 \mathrm{~mm} \& 40 \mathrm{~mm}$, respectively.

With the metasurface decoupling structure the array covers X-band (8.41-8.7 GHz) with bandwidth $(\Delta \mathrm{f})$ of $290 \mathrm{MHz}$ corresponding to a fractional bandwidth (FBW) of $3.4 \%$; Kuband (13.8-14.6 GHz) with $\Delta$ f of $800 \mathrm{MHz}$ and FBW of $5.63 \%$; Ku-band (15.6-17.07 GHz) with $\Delta \mathrm{f}$ of $1.45 \mathrm{GHz}$ and FBW of $8.88 \%$; and bands $\mathrm{Ku}, \mathrm{K}, \& \mathrm{Ka}(17.5-30.0 \mathrm{GHz})$ with $\Delta \mathrm{f}$ of $12.5 \mathrm{GHz}$ and FBW of $52.63 \%$. The maximum and average isolation values in the respective band $(\mathrm{X}, \mathrm{Ku}, \mathrm{K}, \& \mathrm{Ka})$ are 33.6 dB \& $-32.5 \mathrm{~dB} ;-36.45 \mathrm{~dB} \&-33 \mathrm{~dB} ;-30 \mathrm{~dB} \&-27.5 \mathrm{~dB}$; and $-55.3 \mathrm{~dB} \&-44 \mathrm{~dB}$. By comparing the results with the reference array, it is apparent that after applying the proposed integrated decoupling structure the maximum and average suppression in mutual coupling is $7.6 \mathrm{~dB} \& 7 \mathrm{~dB}$ in the first band; $\sim 10 \mathrm{~dB} \& \sim 10 \mathrm{~dB}$ in the second band; $5 \mathrm{~dB} \& 4.5 \mathrm{~dB}$ in the third band; and $\sim 10 \mathrm{~dB}$ and $\sim 10 \mathrm{~dB}$ in the fourth band. Sparameters characteristics of the proposed array antennas are summarized in Table 1. There is very good cohesion in reflection coefficient and mutual coupling responses between the CST Microwave Studio ${ }^{\text {TM }}$ and HFSS.

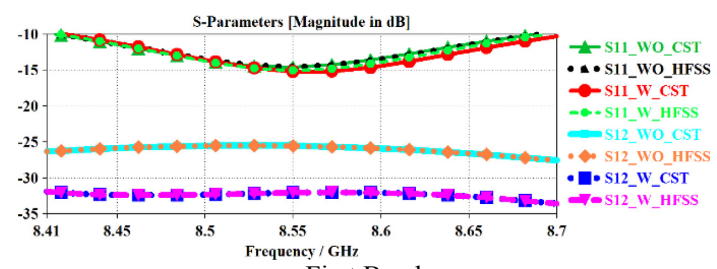

First Band

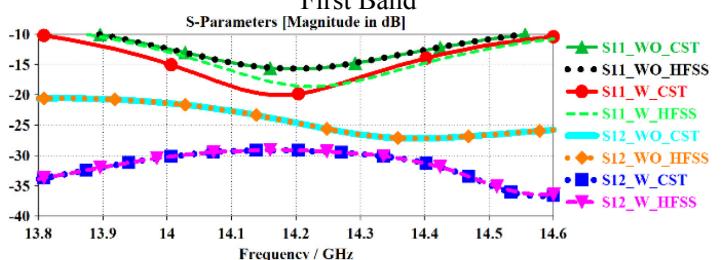

Second Band

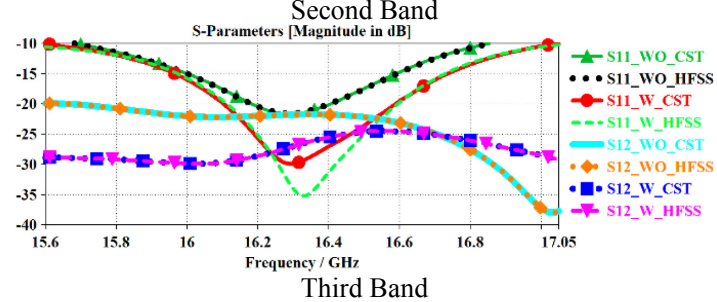

Third Band

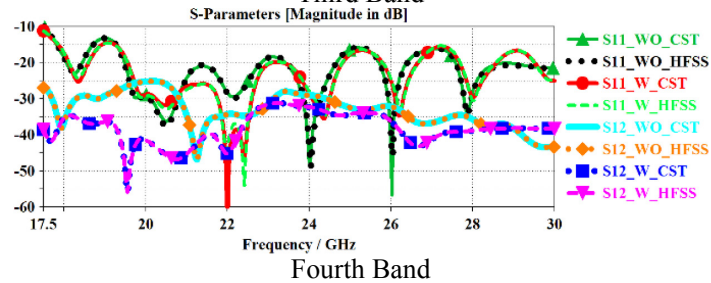

Fig. 2. S-parameters of the reference and proposed array antennas. WO and W represent without and with metasurface isolator, respectively.

Table 1. Suppression of the reference and proposed arrays with no and with metasurface decoupling slab.

\begin{tabular}{|c|}
\hline $\begin{array}{c}\text { First band } \rightarrow 8.41-8.7 \mathrm{GHz}(\Delta \mathrm{f}=290 \mathrm{MHz}, \mathrm{FBW}=3.4 \% \\
\text { Average suppression after applying metasurface isolator: } 7 \mathrm{~dB}\end{array}$ \\
\hline $\begin{array}{c}\text { Second band } \rightarrow 13.8-14.6 \mathrm{GHz}(\Delta \mathrm{f}=800 \mathrm{MHz}, \mathrm{FBW}=5.63 \% \\
\text { Average suppression after applying metasurface isolator: } \sim 10 \mathrm{~dB}\end{array}$ \\
\hline $\begin{array}{c}\text { Third band } \rightarrow 15.6-17.05 \mathrm{GHz}(\Delta \mathrm{f}=1.45 \mathrm{GHz}, \mathrm{FBW}=8.88 \% \\
\text { Average suppression after applying metasurface isolator: } \sim 5 \mathrm{~dB}\end{array}$ \\
\hline $\begin{array}{c}\text { Fourth band } \rightarrow 17.5-30 \mathrm{GHz}(\Delta \mathrm{f}=12.5 \mathrm{MHz}, \mathrm{FBW}=52.63 \% \\
\text { Average suppression after applying metasurface isolator: } \sim 10 \mathrm{~dB}\end{array}$ \\
\hline
\end{tabular}

The equivalent electrical circuit model of the antenna array loaded with the integrated metasurface isolator is shown in Fig. 3 , where the patch radiator is represented with a resonant circuit comprising inductance $L_{P}$, capacitance $C_{P}$, and resistance $R_{P}$. Equivalent circuit of the metasurface isolator is represented by inductance $L_{M}$ and the capacitance $C_{M}$, whose magnitude depend on the gap between the radiators. Coupling between patch and metasurface isolator is through a 


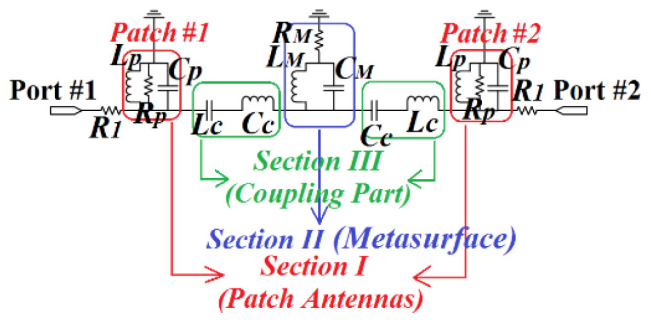

Fig. 3. Equivalent circuit diagram of the proposed $1 \times 2$ array antenna.

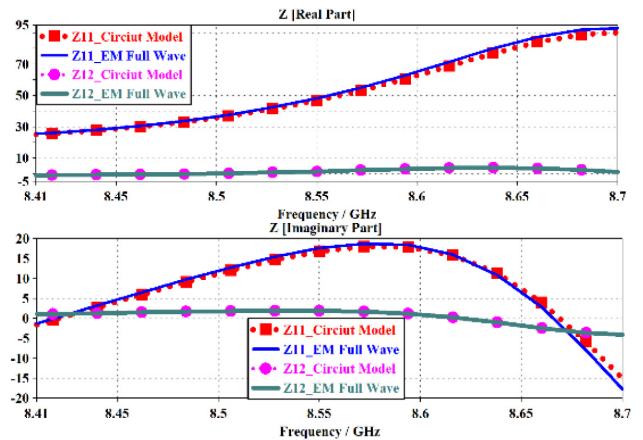

(a) First band
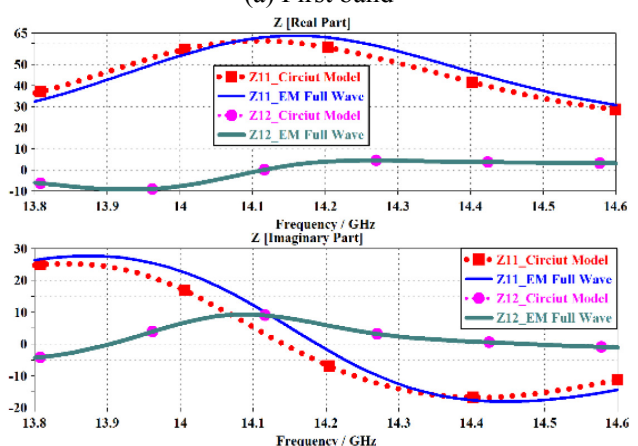

(b) Second band

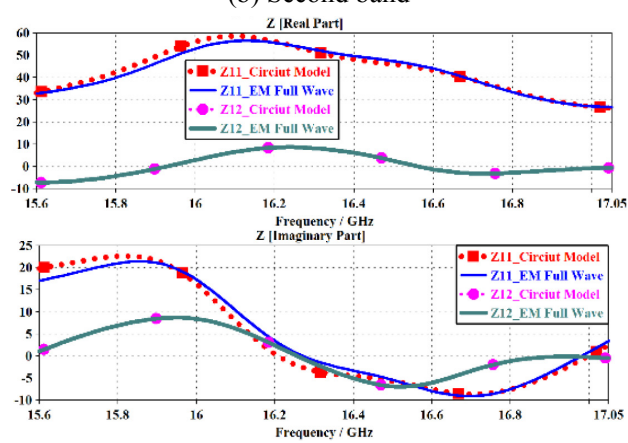

(c) Third band
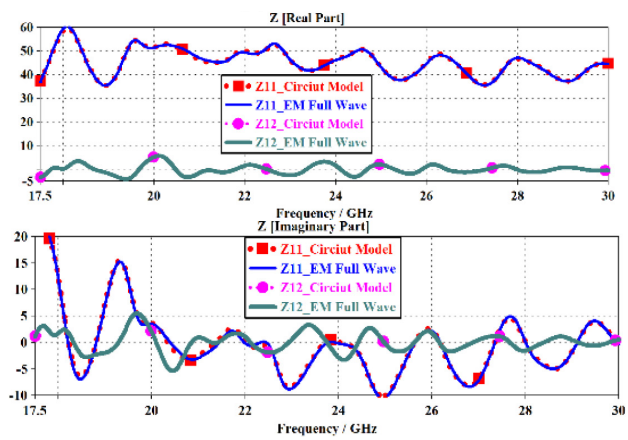

(d) Fourth band

Fig. 4. Input impedances $(\Omega) \&$ admittances $(1 / \Omega)$ of the proposed array. combination of inductance $L_{C}$ and capacitance $C_{C}$. Inductance $L_{C}$ is more dominant because the integrated metasurface isolator is coupled via non-radiating edge of the patch antenna. Ohmic and dielectric loss associated with the metasurface isolator are modelled by resistance $R_{M}$. The resonance frequency $\left(f_{r}\right)$ of the decoupling slab is dependent on the magnitude of inductance $\left(L_{M}\right)$ and capacitance $\left(C_{M}\right)$ given by:

$$
f_{r}=\frac{1}{2 \pi \sqrt{L_{M} C_{M}}}
$$

Optimised values of the equivalent circuit model were extracted using Keysight's ADS software tool and are given in Table 2. The simplified equivalent circuit model is used to determine the effectiveness of the integrated metasurface isolator on the antenna array's return-loss and isolation performance. Input impedance and admittance of the proposed antenna arrays computed using CST are shown in Fig. 4. There is very good correlation in input impedance and admittance response between the circuit model and CST.

Table 2. Optimized values of the equivalent model representing the proposed structure.

\begin{tabular}{|c|c|c|c|c|c|c|c|c|}
\hline$C_{P}$ & $L_{P}$ & $R_{P}$ & $C_{M}$ & $L_{M}$ & $R_{M}$ & $C_{C}$ & $L_{C}$ & $R_{I}$ \\
\hline 2.2 & 11.5 & 50 & 10 & 2.6 & 75 & 14.1 & 1.3 & 85 \\
$\mathrm{pF}$ & $\mathrm{nH}$ & $\Omega$ & $\mathrm{pF}$ & $\mathrm{nH}$ & $\Omega$ & $\mathrm{pF}$ & $\mathrm{nH}$ & $\Omega$ \\
\hline
\end{tabular}

The surface current distributions and radiation properties of the reference and proposed array antenna are plotted in Figs. 5 and 6 , respectively. It is evident from these plots the decoupling structure composed of the square-wave slot soaks up the surface waves that would otherwise couple with the adjacent radiating elements. After applying the proposed isolator based on metasurface the radiation patterns have not been compromised destroyed. In addition, it is observed the radiation patterns with the metasurface decoupling structure approximates the original reference antenna, and over certain angular directions it exhibits better gain performance. The maximum gain of the array antenna with the decoupling slab increased from $5.8 \mathrm{dBi}$ to $7.9 \mathrm{dBi}$ corresponding to $36.2 \%$ improvement. The gain of the reference and proposed array antennas with no and with metasurface decoupling structure varies from $2 \mathrm{dBi}$ to $5.8 \mathrm{dBi}$, and from $3.5 \mathrm{dBi}$ to $7.9 \mathrm{dBi}$, respectively.

Table 3 compares the maximum isolation of the proposed technique with previously published works. Defected ground structure (DGS) and ground-plane slot $[10,11]$ techniques report good improvement in isolation between two antenna elements, however their radiation pattern is significantly deteriorated. Meander line resonator [12] is an appealing choice to reduce surface wave coupling between two elements, without affecting radiation pattern, but these techniques are more complex to design and implement in practice. In [13] the authors have used an electromagnetic band gap (EBG) along with DGS techniques to increase isolation between the radiation elements but this design is also complex to design and fabricate. Besides complexity, acceptable isolation has not achieved. The minimum edge-to-edge gap between the antennas with the proposed technique is $0.28 \lambda$ but it is more than two times with previously reported techniques. 


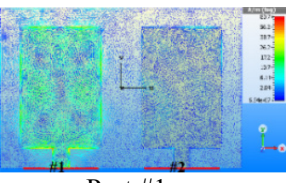

Port \#1

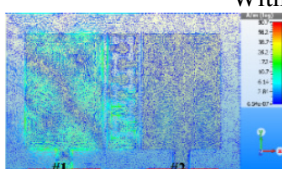

Port \#1

With Isolator@8.5 GHz

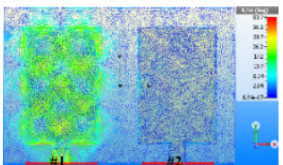

Port \#1

With no Isolator

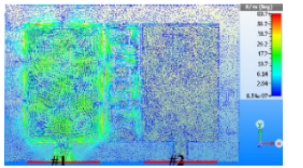

Port \#1

With Isolator@16.0 GHz

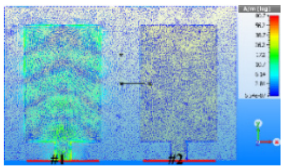

Port \#1

With no Isolator

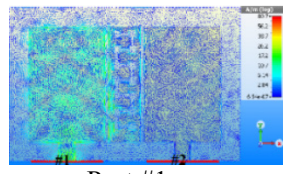

Port \#1

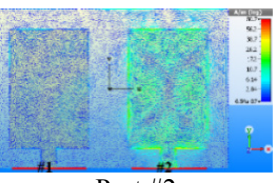

Port \#2

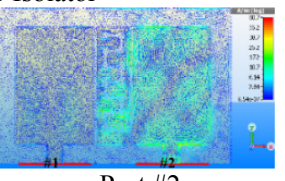

Port \#2

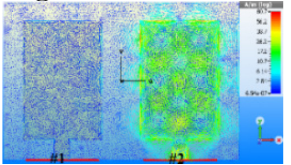

Port \#2
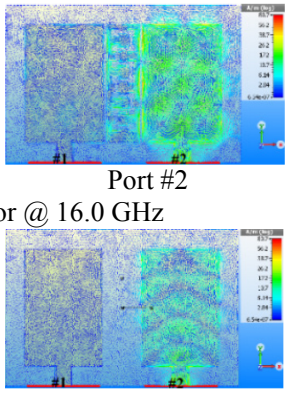

Port \#2

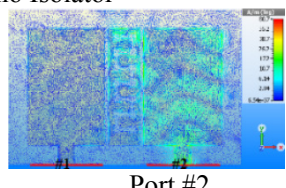

With Isolator@19.5 GHz

Fig. 5. Surface current distribution simulations over the array at various operational frequencies.

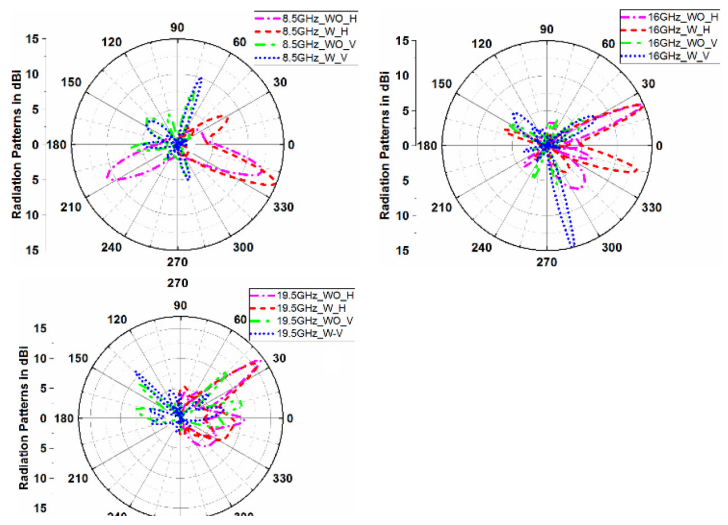

Fig. 6. Radiation patterns of the reference and proposed array antennas without (WO) and with (W) metasurface isolator in the horizontal $(\mathrm{H})$ and vertical (V) planes at various operational frequencies of $8.5,16$, and $19.5 \mathrm{GHz}$.

\section{CONCLUSION}

A unique isolation structure is shown to suppress selfinterference in $1 \times 2$ array antenna. The isolation structure is essentially a metasurface that consists of a square-wave slot pattern with exaggerated corners implemented on a rectangular microstrip patch. When this structure is integrated between the neighbouring two antennas the resulting mutual coupling is suppressed by average of $10 \mathrm{~dB}$ with minimal effect on the radiation characteristics of the array. This technique allows the edge-to-edge gap between the antennas to be reduced to $0.28 \lambda$. Also, the gain is improved by $36 \%$. The proposed technique is cost effective, simple to implement and can be retrofitted. It should be suitable for low-power synthetic aperture radars (SAR) and MIMO systems.

Table 3. Mutual Coupling Isolation Comparison.

\begin{tabular}{|c|c|c|c|c|}
\hline Ref. & Technique & $\begin{array}{c}\text { Max. } \\
\text { Isolation } \\
\text { Improvement }\end{array}$ & Bands & $\begin{array}{c}\text { Radiation } \\
\text { pattern } \\
\text { deterioration }\end{array}$ \\
\hline$[10]$ & SCSRR & $10 \mathrm{~dB}$ & Single & Yes \\
\hline$[11]$ & $\begin{array}{c}\text { U-shaped } \\
\text { resonator }\end{array}$ & $10 \mathrm{~dB}$ & Single & Yes \\
\hline$[12]$ & $\begin{array}{c}\text { Meander line } \\
\text { resonator }\end{array}$ & $10 \mathrm{~dB}$ & Single & No \\
\hline$[13]$ & EBG & $4 \mathrm{~dB}$ & Single & Yes \\
\hline $\begin{array}{c}\text { This } \\
\text { work }\end{array}$ & Metasurface & $10 \mathrm{~dB}$ & Fourth & No \\
\hline
\end{tabular}

\section{ACKNOWLEDGMENT}

This work is partially supported by innovation programme under grant agreement H2020-MSCA-ITN-2016 SECRET722424 and the financial support from the UK Engineering and Physical Sciences Research Council (EPSRC) under grant EP/E022936/1.

\section{REFERENCES}

[1] Choi, J.I., Jain, M., Srinivasan, K., et al.: 'Achieving single channel, full duplex wireless communication', Mobicom'10, IL, USA, Sept. 2010, pp. 1-12.

[2] Alibakhshikenari, M., Virdee, B.S., and Limiti, E.: "A technique to suppress mutual coupling in densely packed antenna arrays using metamaterial supersubstrate', 12th European Conference on Antennas and Propagation (EuCAP 2018), London, 9-13 April 2018.

[3] Xie, J.J., Yin, Y.Z., Wang, J.H., Liu, X.L.: 'Wideband dual-polarized electromagnetic fed patch antenna with high isolation and low crosspolarization', Electron. Lett., 2013, 49, (3), pp. 171-173.

[4] Luo, K., Ding, W., Hu, Y., Cao, W.: 'Design of dual-feed dualpolarized microstrip antenna with high isolation and low cross polarization', Prog. Electromagn. Res. Lett., 2013, 36, pp. 31-40.

[5] Moulder, W.F., Perry, B.T., Herd, J.S.: 'Wideband antenna array for simultaneous transmit and receive (STAR) applications', APS/URSI 2014, TN, USA, July 2014, pp. 243-244.

[6] Fenn, A.J., Hurst, P.T., Herd, J.S., et al.: 'Simultaneous transmit and receive antenna system', US Patent 2013/0106667 A1, May 2013.

[7] Jang, H.S., Lim, W.G., Son, W.I., et al.: 'Microstrip patch array antenna with high isolation characteristic', Microw. Opt. Technol. Lett., 2012, 54, (4), pp. 973-976.

[8] Hall, P.S.: 'Dual circularly polarized sequentially rotated microstrip array with high isolation', Micr. Opt. Tech. Lett., 1992, 5, pp. 236-239.

[9] Batgerel, A., and Eom, S.Y.: 'High-isolation microstrip patch array antenna for single channel full duplex communications', IET Microw. Antennas Propag., 2015, 9, (11), pp. 1113-1119.

[10] Suwailam, M.M.B., Siddiqui, O.F., and Ramahi, O.M.: 'Mutual coupling reduction between microstrip patch antennas using slottedcomplementary split-ring resonators, IEEE Antennas Wireless Propagation Letters, 9, 2019, pp. 876-878.

[11] Farsi, S., Schreurs, D., and Nauwelaers, B.: 'Mutual coupling reduction of planar antenna by using a simple microstrip u-section,' IEEE Ant. \& Wirel. Propag. Lett., 11, 2012, pp. 1501-1503.

[12] Ghosh, J., Ghosal, S., Mitra, D., and S.R.B. Chaudhuri, 'Mutual co4pling reduction between closely placed microstrip patch antenna using meander line resonator', Progress in Electromagnetic Research Letters, 59, 2016, pp. 115-122.

[13] Yu, A., Zhang, X.: 'A novel method to improve the performance of microstrip antenna arrays using a dumbbell EBG structure', IEEE Ant. Wireless Propagation Letters, 2, 9, (1), 2003, pp. 170-172. 